\title{
Goodreads: A social network site for book readers ${ }^{1}$
}

Mike Thelwall, Kayvan Kousha

Statistical Cybermetrics Research Group, University of Wolverhampton, UK.

Goodreads is an Amazon-owned book-based social web site for members to share books read, review books, rate books and connect with other readers. Goodreads has tens of millions of book reviews, recommendations and ratings that may help librarians and readers to select relevant books. This article describes a first investigation of the properties of Goodreads users, using a random sample of 50,000 members. The results suggest that about three quarters of members with a public profile are female, and that there is little difference between male and female users in patterns of behaviour, except for females registering more books and rating them less positively. Goodreads librarians and super users engage extensively with most features of the site. The absence of strong correlations between book-based and social usage statistics (e.g., numbers of friends, followers, books, reviews, and ratings) suggests that members choose their own individual balance of social and book activities and rarely ignore one at the expense of the other. Goodreads is therefore neither primarily a book-based website nor primarily a social network site but is a genuine hybrid, social navigation site.

\section{Introduction}

Goodreads is social website for "readers and book recommendations" (Goodreads 2015a) and has developed a large user base for its niche book-based social web services (Alexa.com rank: $285^{\text {th }}$ most popular site in the world, as of October 2015, according to Alexa.com toolbar users). Goodreads appears to be a social network site based around books because it combines the friend relationship and communication elements of generic social network sites (SNSs), like Facebook (Ellison, 2007), with additional book-related features. This makes Goodreads a social navigation SNS in one typology (Thelwall, 2009b), although a topicfocused SNS might be a better description. Many other SNSs have a similar topic focus, including MySpace, with its music orientation, and Flickr, with its picture orientation. In some cases it is not clear whether a site is primarily an SNS or primarily a topic-focused site with SNS affordances. The overall decision is probably made by a site's members because they can choose which features to ignore, although different members can adopt different overall usage strategies (Brandtzaeg \& Heim, 2011). Hence, in order to understand Goodreads, it is important to assess the extent to which it is a general SNS (which seems unlikely), a book-based social navigation SNS or a book-based site with social features that are largely ignored. Given the potential commercial, library, public and academic interest in the site, the answer to this question will point to the types of insights into reading-related activities, if any, that analyses of the site could provide.

Book reading is a widespread human activity in countries with high literacy levels. Three quarters of American adults (10\% more women than men) have read at least one book in any given year (Zickuhr \& Rainie, 2014) and three quarters of UK adults (16\% more women than men) have read at least one book for pleasure in any given year (Dahlgreen, 2014). Although reading may typically be a solitary activity, books may be discussed before,

\footnotetext{
${ }^{1}$ This is a preprint of an article to be published in the Journal of the Association for Information Science and Technology @ copyright 2016 John Wiley \& Sons, Inc.
} 
during or after reading in ad-hoc and organised ways. As discussed below, there seem to be substantial gender differences in the choice of genres to read, with romances being femaleoriented and science fiction having been historically male-oriented. In this context, it seems likely that there will be at least a partial gender divide in the use of Goodreads and also differences in the extent to which users exploit the social features of the site. In particular, it is not clear whether Goodreads is essentially a social site framed by book reading, a book site with peripheral social affordances, or a combination of the two.

Despite the existence of introductory articles about Goodreads, as discussed below, and one study of gender, commercial success and the number of ratings of books in Goodreads (Verboord, 2011), there is no current data-driven analysis of the site itself. This article fills this gap with a descriptive exploratory analysis of site users, with attention restricted to those with a public profile. The main goal of the study are to identify patterns in the balance between social activities and reading for site users so that Goodreads can be characterised as a general SNS, a book based website or a book-based social navigation SNS. A secondary goal is to assess the importance of gender differences in patterns of site use.

\section{Book reading preferences and gender}

Although more women read books than men (Dahlgreen, 2014; Zickuhr \& Rainie, 2014) the most obvious gender difference is in the choice of books to read. Most academic research into reading preferences by gender has focused on children, often with the goal of informing curriculum development. A survey of adolescents at high schools in central Illinois found that $49 \%$ of females rated romances as their favourite leisure reading in contrast to $3 \%$ of males (Moffitt \& Wartella, 1991). Males preferred fantasy (21\%; females: $5 \%$ ), science fiction (18\%; females: $5 \%$ ) and sports (16\%: females: $2 \%$ ), and females rated reading slightly higher as a leisure activity than did males. Another survey of US pupils found that boys enjoyed reading adventure stories (81\%), humour (64\%), science fiction (57\%) and horror (57\%), whereas girls enjoyed reading romance (68\%), realistic fiction dealing with relationships (65\%), mysteries (59\%) and humour (51\%) (Schultheis, 1990). Similar gender differences have also been found in Australia (Manuel \& Robinson, 2003) and the UK (Hopper, 2005). A later UK study $(n=1512)$ found little difference in the adventure (boys: 62\%; girls: 66\%) and science fiction (boys: 32\%; girls: 26\%) genres (Clark, Torsi, \& Strong, 2005). A later study in Australia also found reduced gender differences, with few girls preferring romances (4\%; boys: $0 \%$ ) and both genders preferring fantasy (girls: $64 \%$; boys: $71 \%$ ) and mystery (girls: $63 \%$; boys: $65 \%$ ) but with males preferring action and adventure (84\%; girls: 38\%) and detective/crime (64\%; girls: 33\%) (Manuel, 2012; Manuel \& Carter, 2015). A possible reason for this dramatic change is the emergence of romantic fantasies, such as the Twilight novels, which may have undermined traditional romances and reclassified a similar kind of reading within the fantasy genre (e.g., Franiuk \& Scherr, 2013) The Harry Potter fantasy novels with strong female characters and relationship themes have probably also influenced the results. Gender differences extend to other types of publications, with many magazines being primarily consumed by one gender (Benton, 1995).

Gender differences are also evident for adult readers. In the USA in 2014, 85\% of books classified as romantic novels were bought by women (Nielsen, 2015). A Goodreads analysis of their readers found that $90 \%$ of the 50 books most read by men were also written by men and $92 \%$ of the 50 books most read by women were also written by women (Flood, 2014). LGBT reading preferences are also likely to exhibit some differences, including a quantity of LGBT-specific fiction (e.g., Clark \& Blackburn, in press). 
Romantic fiction is perhaps the most gendered mainstream fiction genre and is targeted by publishers mainly at women (Radway, 1984). The plot of the stereotypical soft romantic novel is "Young girl meets older dominant male. She is attracted, yet frightened. They become entangled in a relationship in which she feels he dislikes her but in the end after varying degrees of plot complication she finds he loves her", often through a dialog that resolves misunderstandings (Owen, 1997). Readers may use these books to consciously construct a "playful fantasy in which the problems of their lives are resolved in a utopian way," as in a traditional fairy story (Owen, 1997; see also: Wu, 2013). The more realistic approach of chick lit (Harzewski, 2011) may find an audience that rejects this fantasy (Hurst, 2009), or wants to escape from the stigma attached to reading about old fashioned gender roles (Brackett, 2000).

Overall, then, there are strong gender differences in the types of books read, although they may be decreasing for younger readers. These differences may affect the way in which the genders discuss books, who they discuss books with, and the types of bookrelated information that they would find useful. For example, consumers of category romances, such as Mills and Boon (Thomas, 2007), may subscribe to a publisher rather than seeking information about which titles to read.

\section{Social activities related to book reading}

Although book reading can be a private and personal experience, it can also be social, such as with parents reading to children, pupils reading together in a classroom, or couples listening to a book read on the radio. The availability, selection and presentation of books also places them in a wider context so that even solitary readings are not fully alone (Long, $1986,2003)$. Books may also trigger, or be aided by, various types of social interaction. At the simplest level, someone may read book reviews and discuss books and book recommendations with friends. They may also attend book reading groups, perhaps organised by friends, libraries, schools or online. Some reading, such as newspapers, can even have the specific goal of identifying topics for future conversations (Katz, Blumler, \& Gurevitch, 1973).

Book clubs and reading groups are a visible way in which book-based social activities occur. Book clubs recruit more females than males, at least in the USA (Long, 2003). In the UK, girls participate more than boys in most types of reading-related social activities, including reading groups, talking about books and helping with libraries (Clark, Torsi, \& Strong, 2005). Book clubs can be organised as an educational device to encourage reading (Whittingham \& Huffman, 2009) and for bibliotherapy in prisons, psychiatric wards and care homes (Morrison, 2008). Although book club discussions may well be critical and argumentative, they seem to conform carefully to politeness norms (Peplow, 2016). Despite the book focus, however, the primary goal of participants may be to foster intellectual companionship rather than to develop their understanding of literature (Long, 2003).

Online book clubs are technical extensions of offline discussion groups (Foasberg, 2012; Scharber, 2009; Sedo, 2003), with readers sharing book reviews or recommendations "regardless of factors such as cultural or socio-economic background, gender, reading level or geography" (Sedo, 2011, p. 8). Online book reading initiatives may also be harnessed for community building (Harder, Howard, Sedo, 2015) as well as for library activities and book promotion by publishers (Harder, Howard, Sedo, 2015) and can allow direct interactions with a book's author (Gruzd \& Sedo, 2012). Goodreads is sometimes used to help organise online or offline clubs (Hooper, 2014) 
In summary, there is some evidence that social activities related to books are common but are more engaged in by women than by men. Organised book clubs can be set up for a variety of different purposes and can be engaged in for different reasons. Thus, the goal of book-related socialisation is not necessarily to improve the reading experience itself. In this context it is plausible that a book-related social website might have users that focus on its social affordances.

\section{Goodreads}

Goodreads launched officially in January 2007, was listed by Time magazine as one of the top ten sites of 2007 (Sharick, 2007), was bought by Amazon in March 2013 (Olanoff, 2013) and claimed to have over one billion books and 40 million members in October 2015 (Goodreads 2015a). There are other book-based social websites, including LibraryThing (Alexa.com rank: 15,927) and Shelfari (Alexa.com rank: 61,419), but Goodreads (Alexa.com rank: 285) appears to be by far the most popular (O'Leary, 2012). In practice, it probably also competes to some extent with large online bookstores, such as Amazon.com (Alexa.com rank: 6) and Barnes \& Noble (Alexa.com rank: 1,078), that offer social web services, such as membership and the ability to review and rate books. Goodreads is of direct interest to book readers, who are targeted for its services, but, as a site with many readers, it has commercial value for publishers. Because the site contains millions of user reviews of books, it may also inform librarians for purchasing strategies and other services (Blackwell \& Springer, 2013; Tarulli \& Caplinger, 2013; Herther, 2013; Jeffries, 2008; Hooper, 2014; Moyer, 2015; Naik, 2012; Stover, 2009; Wyatt, 2009). Some of the reviews and recommendations are of academic books and so the site may also be useful as a source of evidence about the impact of scholarly books (Zuccala, Verleysen, \& Engels, 2014; Zuccala, Verleysen, Cornacchia, \& Engels, 2015). Nevertheless, the commercial value of the site to publishers and its open nature gives it the potential to be spammed by fake positive reviews, as has been a problem on the Amazon.com site (BBC, 2015).

Like most social network sites, a Goodreads user's profile page includes basic information about them, a list of friends in the site and comments from friends. The top of a profile page (as of November 2015) includes a list of favourite books, any books that the user is currently reading or wants to read and a list of recent book-related profile updates, such as ratings given and books added to lists. This book information is public, except for users with a private profile. Although the data could be primarily used by the owner to keep track of their past and future reading (e.g., via the to-read list), it is also a signal to attract people that like the same type of books. Homophily is important in social networks (Thelwall, 2009a) and it seems likely that book-based common interests would form the basis for friendships in Goodreads. Finding likeminded readers in the site can also be used for collaborative filtering - to get implicit recommendations for new books to read from the lists of people with similar tastes. This could be automatic, via the Goodreads recommendation algorithm, or manual, by browsing lists on profile pages.

Reader comments in Goodreads can provide an important source of information about the changing reception of books by readers (Nakamura, 2013; Desrochers, QuanHaase, Pennington, Laplante, Martin, \& Spiteri, 2013). For example, presence on a book awards shortlist associates with immediately increased numbers of readers, although books tended to start attracting less positive ratings after winning an award (Kovács \& Sharkey, 2014). Data from Goodreads has also been used as the input for experimental book recommender systems research (Liu, Xie, \& Lakshmanan, 2014), as a convenient source of 
quotes from the list provided in the site (Qasim \& Qasim, 2013) and to test an algorithm to detect reviewer spam (Dai, Zhu, Lim, \& Pang, 2012). There has also been one use of Goodreads for impact indicators. An analysis of a sample of history and geography books found a very weak but statistically significant positive correlation between number of Goodreads ratings and the number of Scopus citations, with books being more likely to be rated if more libraries held them (Zuccala, Verleysen, Cornacchia, \& Engels, 2015).

A systematic analysis of a reasonably complete list of 727 books published in February 2009 in the USA that cost at least $\$ 8.50$ compared the number of Amazon.com ratings, the number of Goodreads ratings, and an indicator of the amount of press coverage in the USA with commercial success indicators (Verboord, 2011). The results also showed that a much higher proportion of books received attention in Goodreads than were reviewed in the press, and this was particularly true for mass market paperbacks. Moreover, books by female authors were more likely to be rated online than were books by male authors, suggesting a female bias in the site. The data was consistent with the hypothesis that female authors were more commercially successful than were male authors because they were more often rated online, although further evidence would be needed to confirm this (Verboord, 2011). A study of 10,574 Goodreads biographies matched with Amazon.com found that average book reviews and book reviews per user in Goodreads were higher than in Amazon. Book reviews tended to be much longer on Amazon and with more extreme ratings (Dimitrov, Zamal, Piper, \& Ruths, 2015). An informal content analysis of 50-60 messages posted in each of four of the most popular Goodreads groups found that they were often structured to support information behaviour and had some aspects of a social network (Worrall, 2013). Another paper focused on an acrimonious incident between authors and readers in Goodreads that led to a policy change in the site to disallow the posting of comments about an author's behaviour (Matthews, 2015).

\section{Research Questions}

As discussed in the introduction, Goodreads has the affordances to be a book-based social navigation SNS, but, depending upon how it is used in practice, it could also be a general SNS or a book-based website with social features that are ignored. In practice, there may be some members that use it in one of these three roles. It is therefore important to assess whether users exploiting the social network facilities of the site also exploit the book cataloguing facilities, or whether users tend to focus on one at the expense of the other. As discussed above, gender has been found to influence the types of books rated in Goodreads, with female authors attracting particularly much attention. Female social network site members also seem to be more active than males (Thelwall, 2008). It is therefore logical to investigate Goodreads users for gender differences in activity levels to see whether females tend to use Goodreads in one way (e.g., as a book-based social navigation SNS), whereas males tend to use it as another (e.g., as book based website). The users of any new technology can be expected to differ based upon when they joined (Rogers, 2010; based upon: Ryan \& Gross, 1943) and social network sites evolve over time (Ellison, 2007; Wilkinson \& Thelwall, 2010) and so it is necessary to assess whether the answers vary according to the year of joining. Finally, Goodreads labels some of its users as librarians, and this special category of user should be assessed to understand whether they use it differently - such as being cataloguers that have a particular focus on books (treating Goodreads as a book-based website) or as being helpful librarians (treating Goodreads as a book-based social navigation SNS). A Goodreads librarian is a member who has registered at 
least 50 books in the site, has applied for librarian status, and has had their application approved by Goodreads (Goodreads, 2015). Librarians have editing powers for metadata and images in the site in order to add new information and correct mistakes. Based upon the above issues, the following questions drive this study.

1. How do activity levels in Goodreads vary according to the year of joining?

2. How do book-related activity levels in Goodreads vary with social-related activities for individual users? This is the main research question, designed to give insights into what type of site Goodreads is for most users.

3. Does gender affect the level of engagement of Goodreads users?

4. Do Goodreads librarians engage in the site differently from other users?

\section{Methods}

To get a random sample of Goodreads users, the Goodreads site index was downloaded from https://www.goodreads.com/siteindex.xml in September 2015. This points to a series of files that include an apparently complete list of $16,285,094$ crawlable public webpages in the site. From this list the URLs of homepages of individual users were extracted by identifying the URLs that started with www.goodreads.com/user/show/ (e.g., https://www.goodreads.com/user/show/45905134-mike-thelwall), a total of 5,730,795. From this list of homepages, a random sample of 50,000 was taken by assigning each URL a random number and extracting the smallest 50,000 random numbers. This is therefore a genuine random probability sample of user profile pages. These pages were downloaded by the free web crawler SocSciBot (http://socscibot.wlv.ac.uk) in October 2015, obeying the crawl restrictions in the Goodreads robots.txt file (which did not affect the crawl) and at a rate of one every ten seconds to avoid any risk of overloading the Goodreads server.

The 50,000 downloaded Goodreads user profile pages were parsed by a specially written program to extract profile data and this code has been added to the free Webometric Analyst software (http://lexiurl.wlv.ac.uk, the Get Goodreads User Stats button in the Books tab). This program extracted the core information from each page. Some of the more personal details, such as age, gender, year and month of joining, and month last active, is only available to Goodreads users and not to public visitors, such as a web crawler, and so was not accessed. The public information extracted was the URL, name, the number of friends, followers, books reviewed, books rated, books read, and pictures posted, and whether the user was a Goodreads librarian. All of this information is automatically added to profile pages by Goodreads in a standard format and so could be accurately extracted by the program. For example, the number of ratings is always reported underneath the profile picture, followed by the word "rating" or "ratings" and preceded by an HTML link anchor with a unique format (pointing to a page listing the user's reviews, sorted by their ratings).

Some pages could not be downloaded and an investigation of a sample of these found that the profile URLs all redirected to a different URL for the same person registered as an author rather than a reader. Some of the profiles were private and revealed little information (name, books read, and if a Goodreads librarian), but most were public.

Since user genders are needed, a first name matching technique was used to guess users' genders. Since most users with a registered address appeared to be from the USA, gender was inferred from first (given) names for this demographic. From a 1990 census list of common male and female names in the USA, a list of gendered first names was created from those for which either $90 \%$ were male or $90 \%$ were female. This produced 4,958 gendered names, 1,021 of which were male, and 3,937 of which were female. The excess 
number of female names reflects a greater variety in the use of female names rather than a more exhaustive search for female names. Matching this information with user names in profile pages, $62 \%$ of the non-missing profiles were allocated a gender $(30,162)$. Some of the gender inferences will be incorrect because the user switched their apparent gender online, had a minority gender name, or used a nickname that associated with a different gender (e.g., Ali for Alison, Sam for Samantha, Nick for Nicola). This method will not give an accurate estimate of gender proportions in the corpus since it seems likely that one gender will tend to use more strongly gendered names than the other, but should give a very approximate estimate and will be useful for comparing properties of male users against properties of female users.

Information about the joining date for each user is only available to Goodreads members but can be inferred from the Goodreads ID of each user, which is part of their profile. The IDs are given in consecutive order by date and so a lookup table can be used to convert an ID into a year. Table 1 was constructed by a Goodreads member checking profile URLS to identify the approximate cut-off between one year and the next. This table was used to assign a joining year to each user. Note that the number of unique Goodreads user profile URLs (16 million) in the official sitemap is substantially greater than the number of unique user IDs from the site (over 38 million by the end of 2014), which may be due to members leaving or changing their profile or the IDs being used for other purposes.

Table 1. User IDs and numbers of IDs per year for the entire Goodreads site.

\begin{tabular}{|l|l|l|}
\hline Year & Approx. end ID & Approx. number of IDs \\
\hline 2006 & 454 & 454 \\
\hline 2007 & 730560 & 730,107 \\
\hline 2008 & 1850625 & $1,120,066$ \\
\hline 2009 & 3094600 & $1,243,976$ \\
\hline 2010 & 4731400 & $1,636,801$ \\
\hline 2011 & 7299250 & $2,567,851$ \\
\hline 2012 & 15961000 & $8,661,751$ \\
\hline 2013 & 27198500 & $11,237,501$ \\
\hline 2014 & 38598750 & $11,400,251$ \\
\hline
\end{tabular}

Since all the count data collected was highly skewed, statistical tests based on the normal distribution would be inappropriate and so non-parametric methods were used instead, such as Spearman correlations. For the same reason, the geometric mean was used instead of the arithmetic mean. This is substantially less affected by skewing than the arithmetic mean and is also a reasonable measure of central tendency. The geometric mean can only be used for non-zero data and so the standard method of adding one to the data before calculations, and then subtracting 1 from the result was used. In other words, for a sample $x_{1}, x_{2}, \ldots x_{n}$, the geometric mean is $\exp \left(\frac{\sum_{i=1}^{n} \ln \left(x_{i}+1\right)}{n}\right)-1$. Confidence intervals can also be calculated for the geometric mean using the normal distribution formula applied to the log transformed data $\ln \left(x_{1}+1\right), \ln \left(x_{2}+1\right), \ldots \ln \left(x_{n}+1\right)$ to get a lower limit $l_{95}$ and upper limit $u_{95}$ for the log transformed data and the same inverse procedure gives confidence limits $\exp \left(l_{95}\right)-1$ and $\exp \left(u_{95}\right)-1$ for the geometric mean. These limits assume that the log transformed data is approximately normal but this is not the case for some of the variables: follower counts (e.g., for 2012, skewness=3, kurtosis=13), photographs (e.g., for 
2012, skewness $=12$, kurtosis=180), and average ratings (not using the log transformation), (e.g., for 2012, skewness=-3, kurtosis=10). The number of reviews also did not have an approximately normal distribution for 2013-2015 (e.g., for 2013, skewness=2, kurtosis=5). For the other variables and years, the skewness and kurtosis values were between -2 and +2 , which is within the acceptable range for the normal distribution. Statistics were calculated for all cases, but the confidence intervals for non-normal variables should be interpreted with caution.

\section{Results}

As shown in Table 2, almost all users have a public profile (93.5\% of non-missing users). The year 2012 was selected for more detailed analyses because it is the oldest year with substantial numbers of users.

Table 2. Sample sizes for the joining year of users, by type of profile.

\begin{tabular}{|l|r|r|r|r|}
\hline Joining Year & \multicolumn{1}{|c|}{ Public } & Private & Missing & \multicolumn{1}{c|}{ Total } \\
\hline 2006 & 1 & 0 & 0 & 1 \\
\hline 2007 & 456 & 66 & 22 & 544 \\
\hline 2008 & 872 & 110 & 42 & 1,024 \\
\hline 2009 & 920 & 170 & 47 & 1,137 \\
\hline 2010 & 1,255 & 228 & 58 & 1,541 \\
\hline 2011 & 2,747 & 419 & 126 & 3,292 \\
\hline 2012 & 8,332 & 579 & 177 & 9,088 \\
\hline 2013 & 9,472 & 386 & 161 & 10,019 \\
\hline 2014 & 9,362 & 251 & 154 & 9,767 \\
\hline 2015 & 13,341 & 150 & 96 & 13,587 \\
\hline Total & 46,758 & 2,359 & 883 & 50,000 \\
\hline
\end{tabular}

\section{Changes in levels of activity by year of joining}

Unsurprisingly, newer users have the lowest total activity statistics. This is true for the number of books read (Figure 1), ratings (Figure 2), book reviews (Figure 4), friends (Figure 5), and followers (Figure 6). There is no apparent pattern in the number of photographs uploaded per user (Figure 7), probably because very few users ever upload any. There is a trend for the early and recent joiners to give slightly higher ratings to books than other users (Figure 3), but except for 2015 the differences are at the margins of statistical significance. 


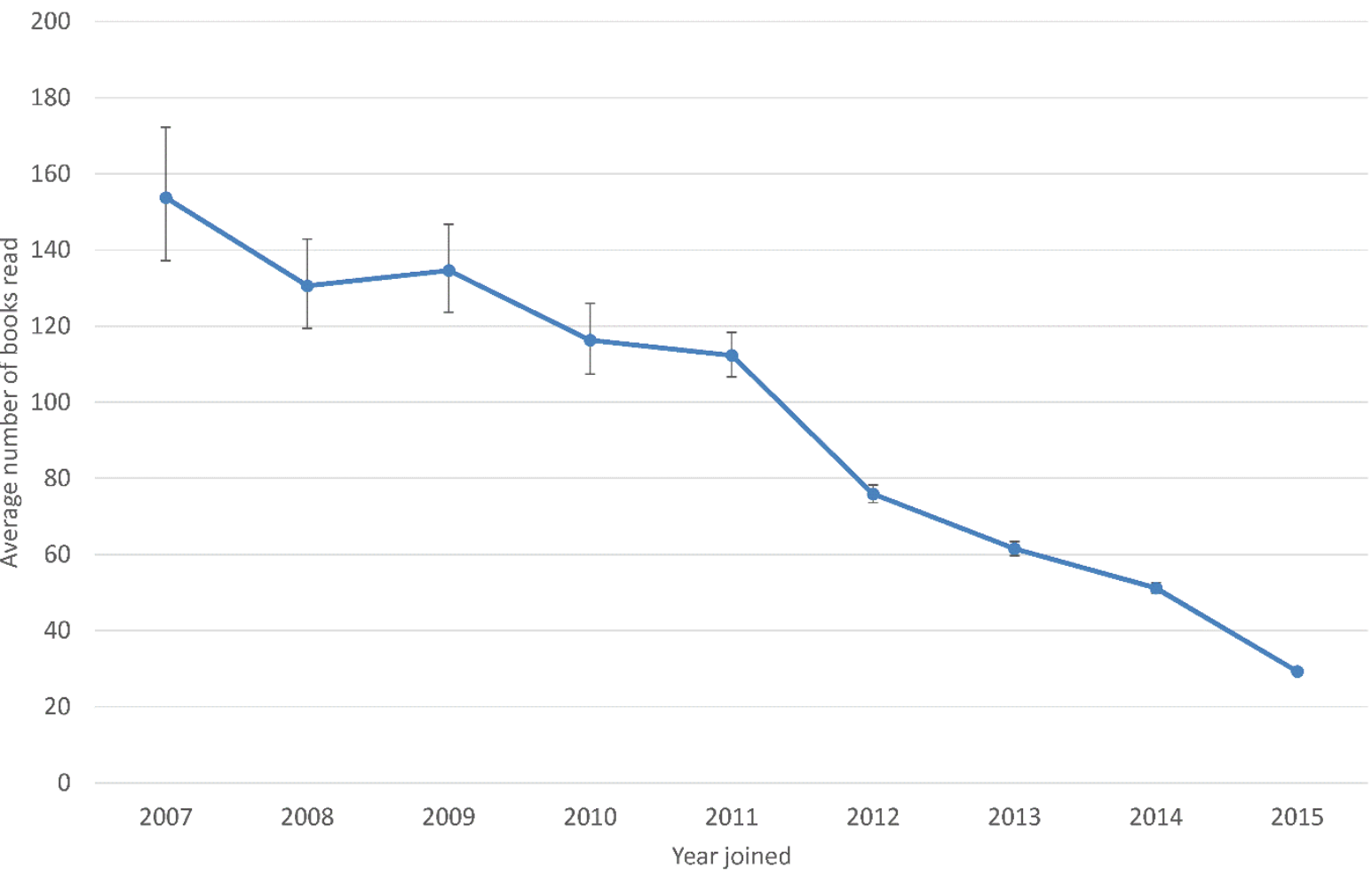

Figure 1. Average (geometric mean) number of books read per user, by year of joining Goodreads for all non-missing users in the sample $(n=49,117)$. Error bars show $95 \%$ confidence intervals.

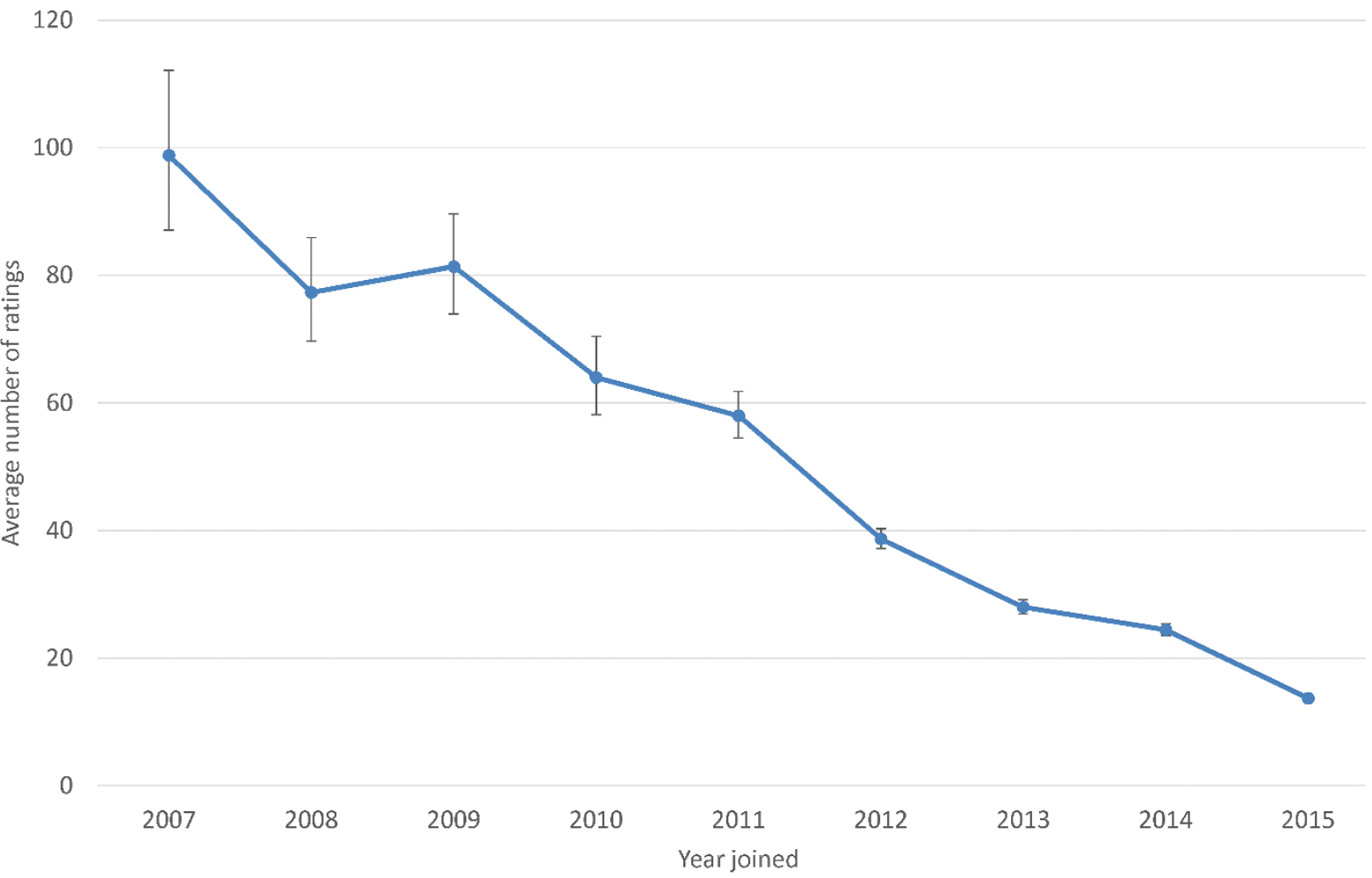

Figure 2. Average (geometric mean) number of book ratings given per user, by year of joining Goodreads for all users in the sample with public profiles $(n=46,758)$. Error bars show $95 \%$ confidence intervals. 


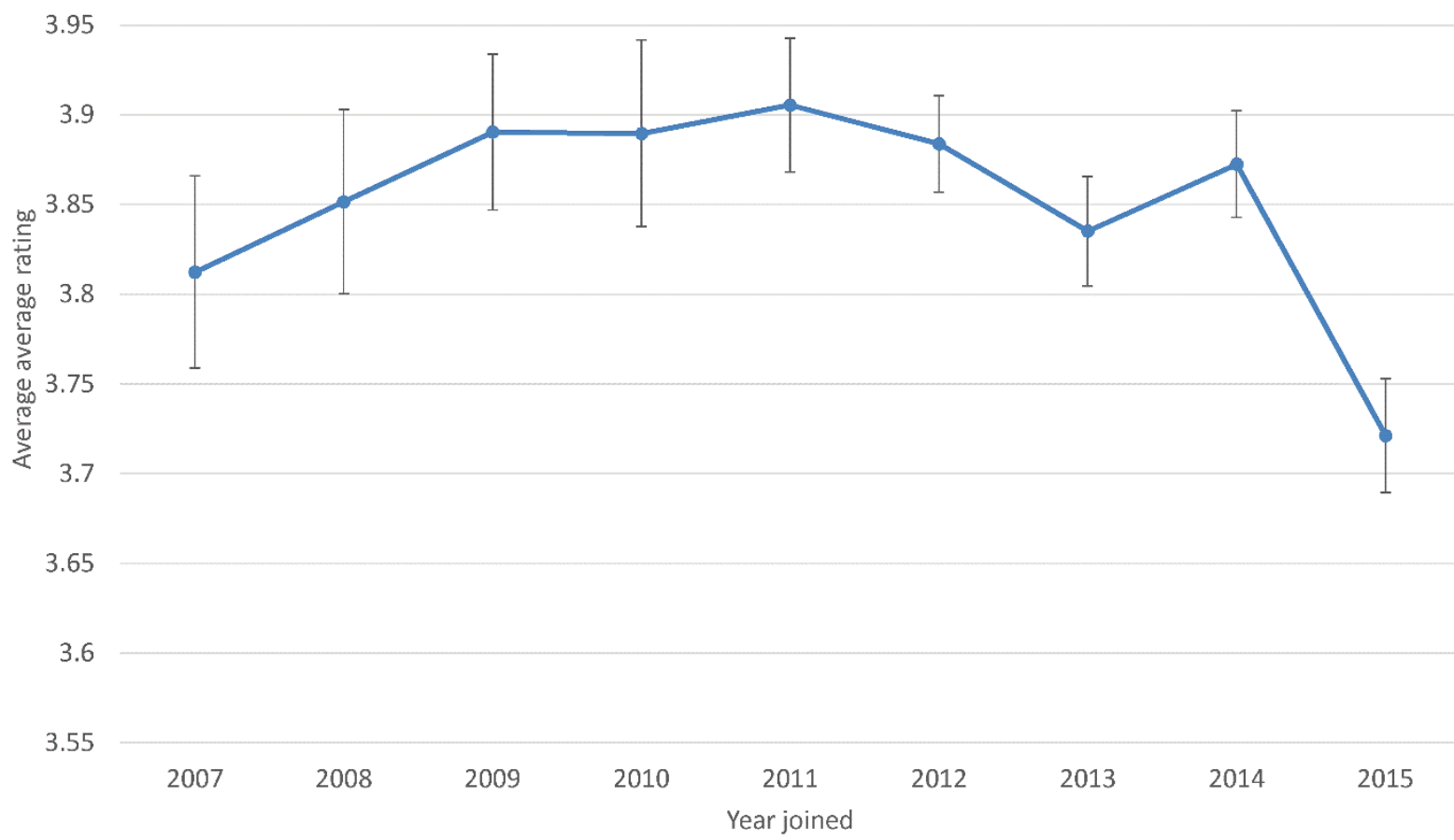

Figure 3. Average (arithmetic mean) star ratings given to books per user, by year of joining Goodreads for all users in the sample with public profiles $(n=46,758)$. Error bars show $95 \%$ confidence intervals.

12

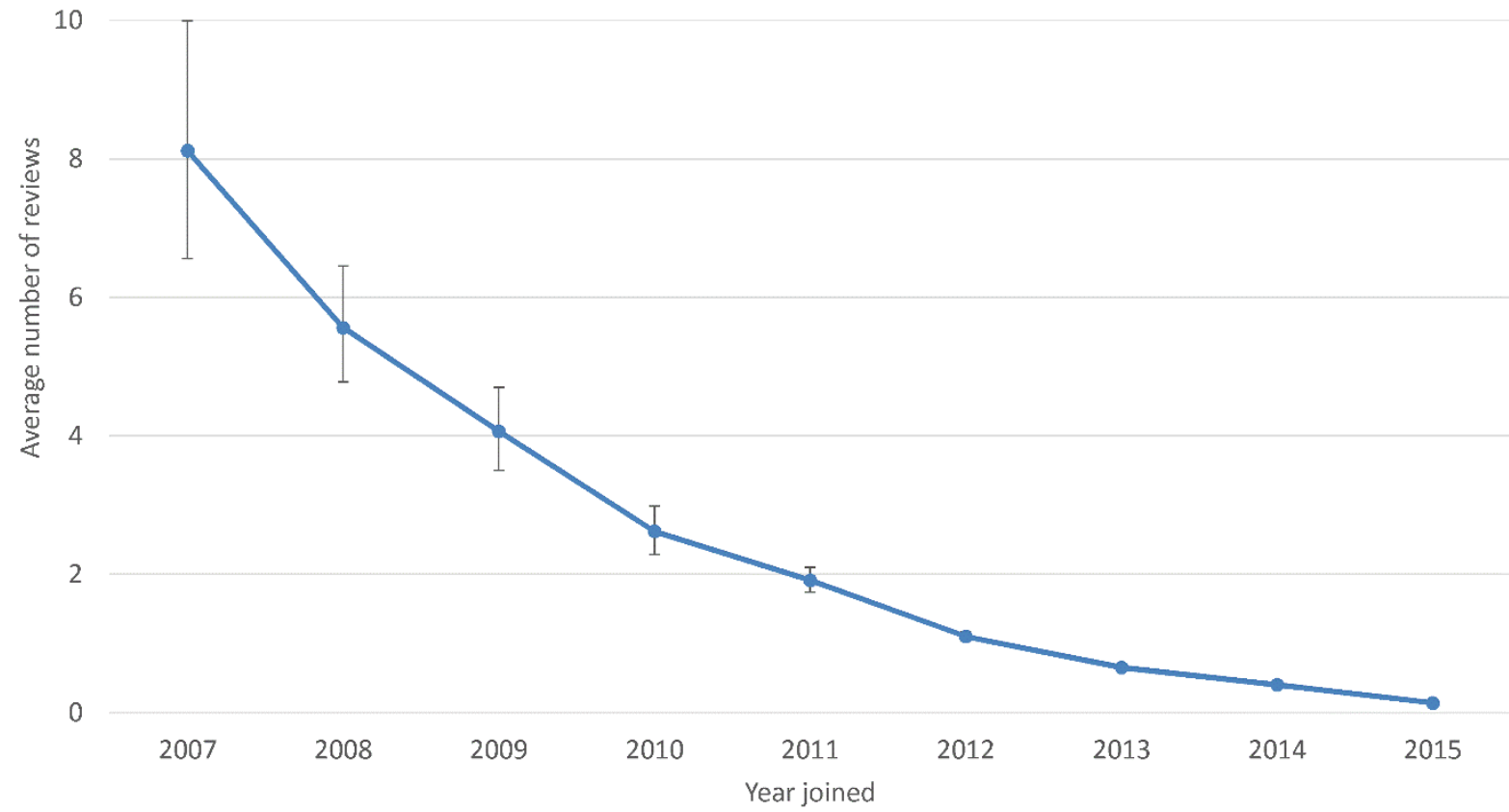

Figure 4. Average (geometric mean) number of book reviews written per user, by year of joining Goodreads for all users in the sample with public profiles $(n=46,758)$. Error bars show $95 \%$ confidence intervals. 


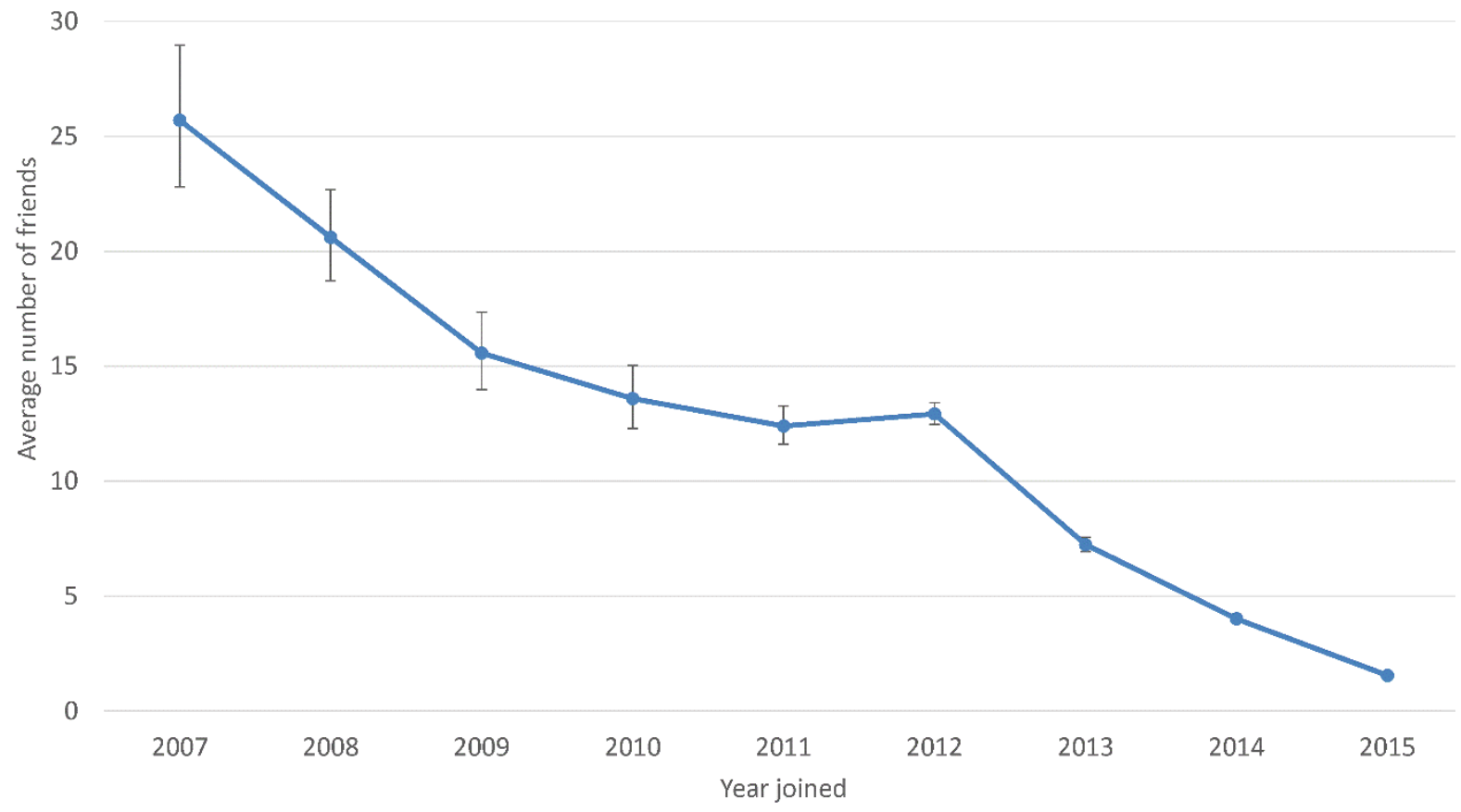

Figure 5. Average (geometric mean) number of Friends per user, by year of joining Goodreads for all users in the sample with public profiles $(n=46,758)$. Error bars show $95 \%$ confidence intervals.

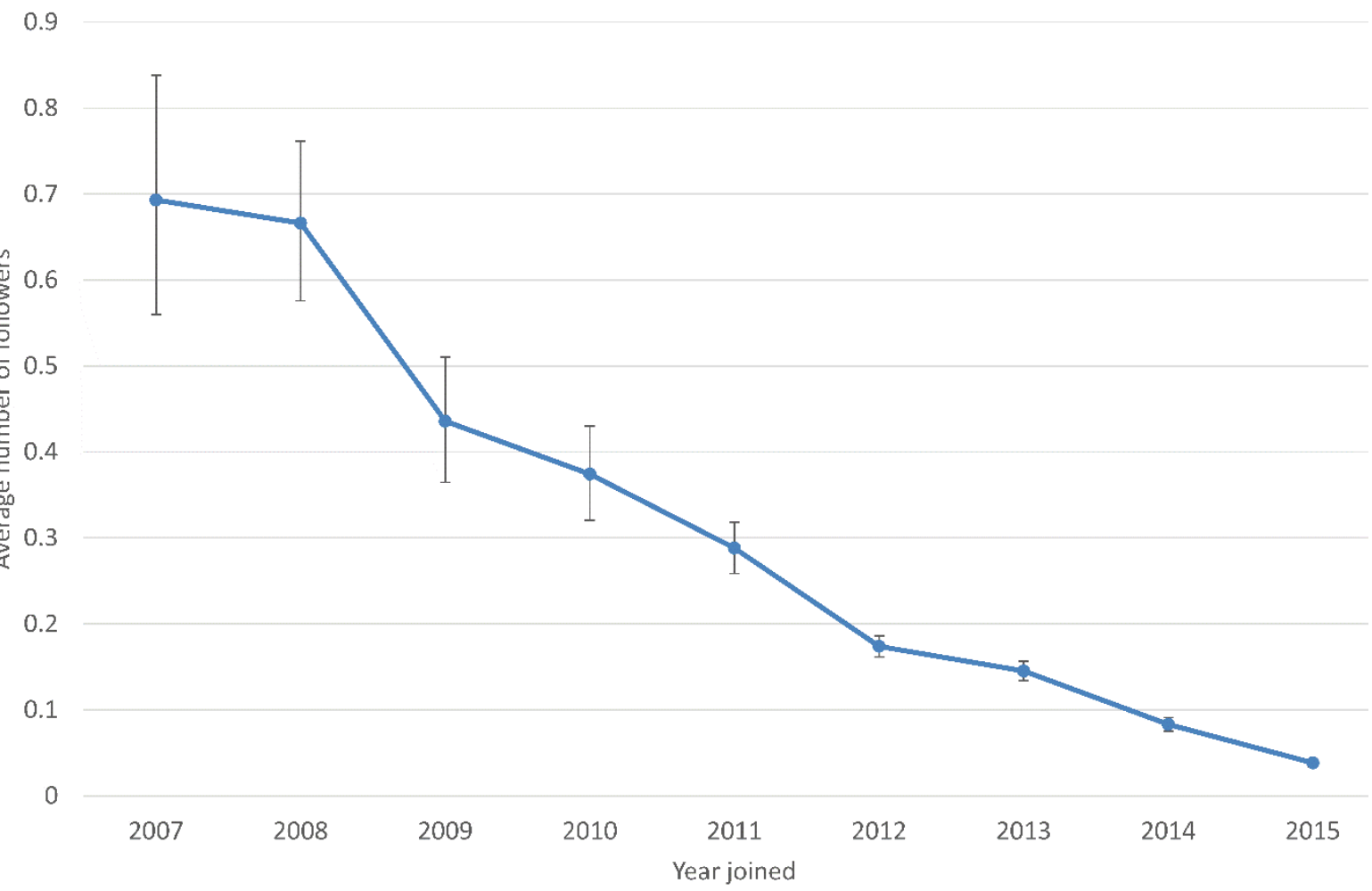

Figure 6. Average (geometric mean) number of Followers per user, by year of joining Goodreads for all users in the sample with public profiles $(n=46,758)$. Error bars show $95 \%$ confidence intervals. 


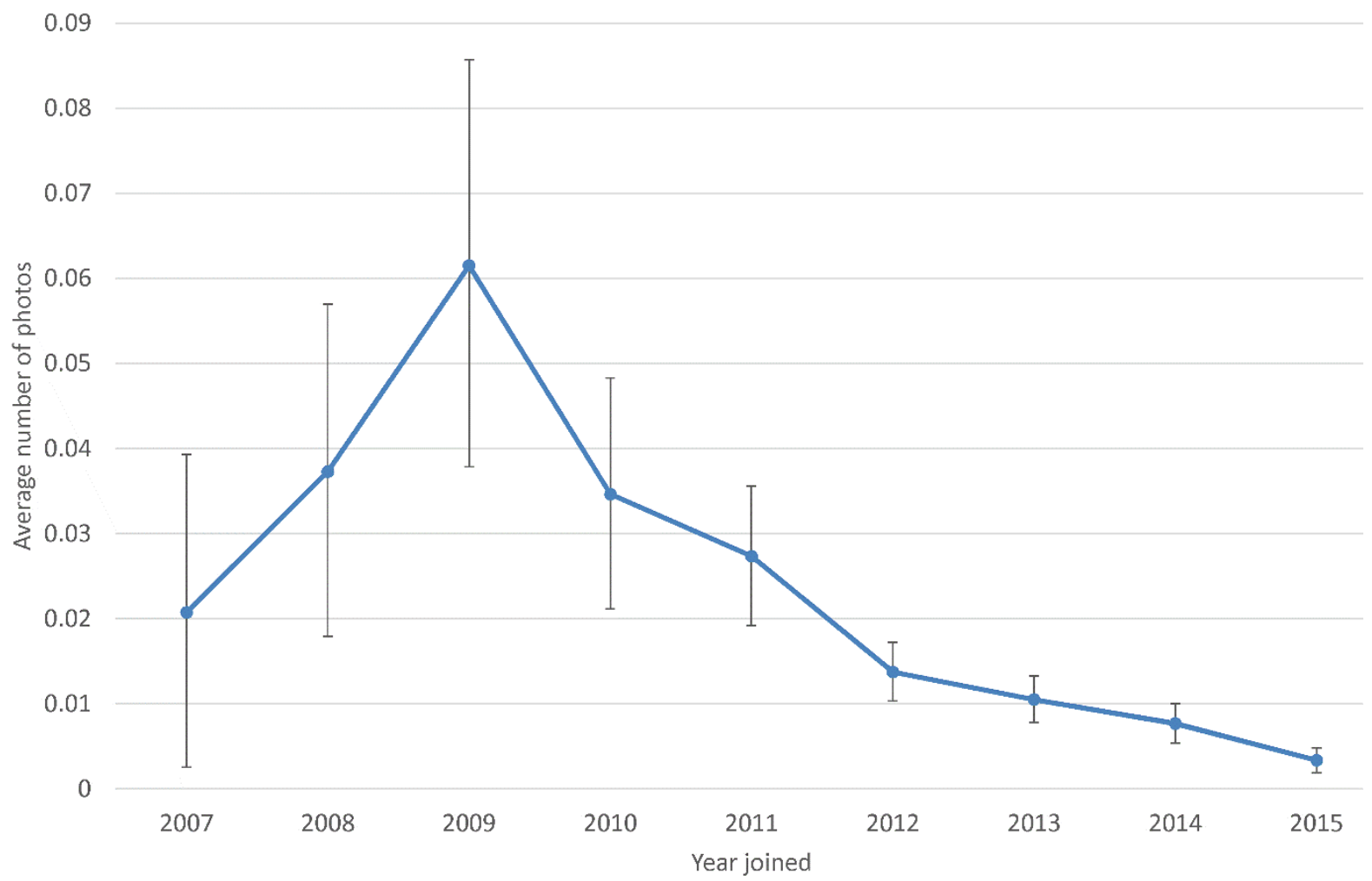

Figure 7. Average (geometric mean) number of photographs uploaded per user, by year of joining Goodreads for all users in the sample with public profiles $(n=46,758)$. Error bars show $95 \%$ confidence intervals.

\section{Relationships between different types of activities}

Spearman correlations (Table 3) were calculated between all pairs of numerical variables for users that joined in 2012 (the first year with large numbers of users). These correlations can give insights into the extent to which users tend to use one feature based on the extent to which they use another. Since there is a 12 month difference between the first and last user joining, the user ID was also correlated with the other variables to suggest the extent to which a correlation may be affected by this time difference. The Goodreads user ID has a mostly low correlation with the other variables, except for the number of ratings given (0.122 ) and so this is the main variable with a substantial time variation within 2012.

There are very low correlations between books read and friends/followers. People that read a lot of books, or at least register a lot of books, therefore do not tend to have substantially more friends in the site. It may be that some people employ Goodreads to record the books that they have read or use it as a book recommendation service since it recommends new books based on previously read books. The low correlation between average rating and number of ratings is also surprising. It seems likely that new users would enter their favourite books to start with and give them a high rating, with subsequent books added getting more moderate ratings. Conversely, there may also be users that give initially moderate ratings by interpreting the Goodreads star descriptions at face value, whereas they may rate more generously later on as a strategic choice, because most ratings in the site seem to be high. There is no evidence that either of these happen but it is possible that both do to some extent and cancel each other out. There is also a relatively low correlation between the number of books read and the number of book reviews written. A possible explanation for this is that some users only register a book in the site if they want to review 
it, so they review a large proportion of their registered books, whereas other users may register many books but only review a select few. Overall, however, the generally low correlations suggest that users selectively use the features of Goodreads in order to exploit the site for relatively narrow goals, rather than attempting to fully engage with it.

Table 3. Spearman correlations between data extracted from users in 2012 (the first big year) with public profiles ( $n=8,332$ ).

\begin{tabular}{|c|c|c|c|c|c|c|c|c|}
\hline & ID & $\begin{array}{l}\text { Books } \\
\text { read }\end{array}$ & Ratings & $\begin{array}{l}\text { Av. } \\
\text { rating }\end{array}$ & Reviews & Friends & Follow. & Photos \\
\hline ID & 1 & $-.098 * *$ & $-.122 * *$ & 0.012 & $-.083 * *$ & $-.085 * *$ & $-.035 * *$ & -0.015 \\
\hline Books read & & 1 & $.880 * *$ & $-.062 * *$ & $.346 * *$ & $.045^{* *}$ & $.059 * *$ & $.105^{* *}$ \\
\hline Ratings & & & 1 & $-.029 * *$ & $.354^{* *}$ & $.045^{* *}$ & $.057^{* *}$ & $.086 * *$ \\
\hline $\begin{array}{l}\text { Average } \\
\text { rating }\end{array}$ & & & & 1 & -0.017 & $.045^{* *}$ & -0.013 & -0.02 \\
\hline Reviews & & & & & 1 & $.164^{* *}$ & $.096 * *$ & $.111^{* *}$ \\
\hline Friends & & & & & & 1 & $.246 * *$ & $.065 * *$ \\
\hline Followers & & & & & & & 1 & $.069 * *$ \\
\hline Photos & & & & & & & & 1 \\
\hline
\end{tabular}

** Significant with $p<0.01$

\section{Gender}

About three quarters of Goodreads users seem to be female (Table 4) but this is a very approximate figure due to the simplifying assumptions used to estimate the gender split in the data. There does not seem to have been a substantial gender shift in the site over time, although the decreasing proportion of users with a gender identifiable from the American first names list suggests that the users of Goodreads have become more international over time.

Table 4. Goodreads user inferred gender, by joining year, for all non-missing users in the sample $(n=49,117)$.

\begin{tabular}{|l|l|l|l|l|l|l|l|l|l|l|l|}
\hline Joined & $\mathbf{2 0 0 6}$ & $\mathbf{2 0 0 7}$ & $\mathbf{2 0 0 8}$ & $\mathbf{2 0 0 9}$ & $\mathbf{2 0 1 0}$ & $\mathbf{2 0 1 1}$ & $\mathbf{2 0 1 2}$ & $\mathbf{2 0 1 3}$ & $\mathbf{2 0 1 4}$ & $\mathbf{2 0 1 5}$ & Total \\
\hline Male & 0 & 99 & 166 & 163 & 242 & 473 & 1,313 & 1,468 & 1,404 & 2,013 & 7,341 \\
\hline Female & 1 & 299 & 558 & 590 & 724 & 1,645 & 4,485 & 4,543 & 4,317 & 5,659 & 22,821 \\
\hline Total & $\mathbf{1}$ & $\mathbf{3 9 8}$ & $\mathbf{7 2 4}$ & $\mathbf{7 5 3}$ & $\mathbf{9 6 6}$ & $\mathbf{2 , 1 1 8}$ & $\mathbf{5 , 7 9 8}$ & $\mathbf{6 , 0 1 1}$ & $\mathbf{5 , 7 2 1}$ & $\mathbf{7 , 6 7 2}$ & $\mathbf{3 0 , 1 6 2}$ \\
\hline Female \% & $100 \%$ & $\mathbf{7 5 \%}$ & $\mathbf{7 7 \%}$ & $\mathbf{7 8 \%}$ & $\mathbf{7 5 \%}$ & $\mathbf{7 8 \%}$ & $\mathbf{7 7 \%}$ & $\mathbf{7 6 \%}$ & $\mathbf{7 5 \%}$ & $\mathbf{7 4 \%}$ & $\mathbf{7 6 \%}$ \\
\hline Unknown & 0 & 124 & 258 & 337 & 517 & 1,048 & 3,113 & 3,847 & 3,892 & 5,819 & 18,955 \\
\hline
\end{tabular}

Since the gender proportions do not vary much over time, it seems reasonable to analyse all years together for gender (Table 5). The results show that female users tend to register more books as read in the site than do male users, although the difference is not large ( 8 more books, or an increase of $16 \%)$. Male users seem to give higher average ratings than do female users and this difference is also not large $(0.07$ from a possible range of 4 , from 1 to 5 stars). In contrast to other social networks (e.g., Thelwall, 2008), it is surprising that females do not have more friends and followers than do males. 
Table 5. Average user values by gender for all users with public profiles and an inferred gender ( $n=28,607)$. The geometric mean is used for all except the average rating, which uses the arithmetic mean. Bold values suggest statistically significant differences with nonoverlapping confidence intervals.

\begin{tabular}{|l|l|l|}
\hline Statistic & Males & Females \\
\hline Books read & $\mathbf{5 0 . 1}(48.8,51.5)$ & $\mathbf{5 8 . 0}(57.0,58.9)$ \\
\hline Ratings given & $27.3(26.3,28.2)$ & $27.3(26.7,27.9)$ \\
\hline Average rating* & $\mathbf{3 . 8 8}(3.85,3.90)$ & $\mathbf{3 . 8 1}(3.80,3.83)$ \\
\hline Reviews written* & $0.7(0.6,0.7)$ & $0.7(0.7,0.8)$ \\
\hline Friends & $5.7(5.4,5.9)$ & $5.6(5.5,5.7)$ \\
\hline Followers* & $0.2(0.1,0.2)$ & $0.1(0.1,0.1)$ \\
\hline Photos uploaded* & $0.0(0.0,0.0)$ & $0.0(0.0,0.0)$ \\
\hline
\end{tabular}

*Confidence intervals are approximations due to non-normal data and should be treated with caution

Despite the above gender differences, the relationships between variables are similar for male and female users in the sense that correlations between variables do not differ much when restricted to only males and when restricted to only females, and the correlations are not systematically stronger for one gender than the other (Table 6).

Table 6. Spearman correlations from Table 3 calculated separately for male and female users. The data is for users with public profiles that joined in 2012 and for which a gender was inferred from their first name (top row: females, $n=4,161$; bottom row: males, $n=1,251$ ). The largest correlation from each gender pair is in bold.

\begin{tabular}{|c|c|c|c|c|c|c|c|}
\hline & Ratings & Reviews & Photos & \begin{tabular}{|l|} 
Average \\
rating
\end{tabular} & Friends & $\begin{array}{l}\text { Books } \\
\text { read }\end{array}$ & Followers \\
\hline Ratings (f) & 1 & $0.338 * *$ & $0.076 * *$ & $-0.048 * *$ & 0.099** & $0.886 * *$ & $0.068 * *$ \\
\hline$(\mathrm{m})$ & 1 & $0.350 * *$ & 0.054 & $-0.067^{*}$ & -0.007 & $0.878 * *$ & 0.035 \\
\hline Reviews (f) & & 1 & $0.095 * *$ & -0.011 & $0.163^{* *}$ & $0.330 * *$ & $0.081 * *$ \\
\hline (m) & & 1 & $0.101 * *$ & -0.049 & $0.170 * *$ & $0.331 * *$ & $0.074^{* *}$ \\
\hline Photos (f) & & & 1 & -0.011 & 0.024 & $0.098 * *$ & 0.012 \\
\hline (m) & & & 1 & -0.003 & 0.075 & $0.081 * *$ & $0.082 * *$ \\
\hline Average rating (f) & & & & 1 & $0.051^{* *}$ & $-0.066 * *$ & -0.001 \\
\hline (m) & & & & 1 & $0.081 * *$ & $-0.143 * *$ & 0.046 \\
\hline Friends $(f)$ & & & & & 1 & $0.095^{* *}$ & $0.217^{* *}$ \\
\hline (m) & & & & & 1 & 0 & $0.241 * *$ \\
\hline Books read (f) & & & & & & 1 & $0.064 * *$ \\
\hline (m) & & & & & & 1 & 0.038 \\
\hline Followers (f) & & & & & & & 1 \\
\hline (m) & & & & & & & 1 \\
\hline
\end{tabular}

* Significant with $p<0.5 ; * *$ Significant with $p<0.01$.

\section{Librarians}

Goodreads librarians are a small minority of users (1\%) and are even rarer amongst people that joined Goodreads recently (Table 7). 
Table 7. The prevalence of Goodreads librarians, by joining year, for all non-missing users in the sample $(n=49,117)$.

\begin{tabular}{|l|l|l|l|l|l|l|l|l|l|l|l|}
\hline Join year & 2006 & 2007 & 2008 & 2009 & 2010 & 2011 & 2012 & 2013 & 2014 & 2015 & Total \\
\hline Librarian & 1 & 23 & 36 & 21 & 48 & 53 & 63 & 38 & 7 & 1 & 291 \\
\hline Total users & 1 & 522 & 982 & 1,090 & 1,483 & 3,166 & 8,911 & 9,858 & 9,613 & 1,3491 & 49,117 \\
\hline Librarian $\%$ & $100 \%$ & $4 \%$ & $4 \%$ & $2 \%$ & $3 \%$ & $2 \%$ & $1 \%$ & $0 \%$ & $0 \%$ & $0 \%$ & $1 \%$ \\
\hline
\end{tabular}

Librarians tend to be more active users in all aspects of Goodreads (Table 8). They read, review and rate more books and have more friends and followers. Some of these friends and followers may originate from socialising with other Goodreads librarians as part of learning the role or exchanging role-related information and advice.

Table 8. Average user values by Goodreads librarian status for all users with public profiles in 2012 ( $n=8,332$ ). The geometric mean is used for all except the average rating, which uses the arithmetic mean. Bold values suggest statistically significant differences with nonoverlapping confidence intervals.

\begin{tabular}{|l|l|l|}
\hline & Not librarian & Librarian \\
\hline Books read & $\mathbf{7 8 . 5}(76.1,81.0)$ & $\mathbf{4 1 1 . 4}(283.2,597.4)$ \\
\hline Ratings given & $\mathbf{3 9 . 9}(38.3,41.5)$ & $\mathbf{1 7 9 . 5}(98.7,325.8)$ \\
\hline Average rating* & $3.89(3.86,3.91)$ & $3.77(3.35,4.19)$ \\
\hline Reviews written* & $\mathbf{1 . 1}(1.1,1.2)$ & $\mathbf{9 . 5}(3.6,22.9)$ \\
\hline Friends & $\mathbf{1 3 . 0}(12.5,13.4)$ & $\mathbf{2 9 . 1}(16.1,51.9)$ \\
\hline Followers* & $\mathbf{0 . 2}(0.2,0.2)$ & $\mathbf{1 . 1}(0.3,2.3)$ \\
\hline Photos uploaded* & $0.0(0.0,0.0)$ & $0.2(0.0,0.4)$ \\
\hline
\end{tabular}

${ }^{*}$ Confidence intervals are approximations due to non-normal data and should be treated with caution

A slightly higher proportion of males are librarians than are females. In 2012, $0.9 \%$ of males (11) and $0.4 \%$ of females (17) were librarians. Overall, $0.8 \%$ of males (61) and $0.4 \%$ of females (94) were librarians. The former difference is statistically significant with $p<0.05$ and the latter with $p<0.01$, using a chi-square test. Hence, although more librarians are female than are male, male users are more likely to become librarians.

\section{Discussion and limitations}

Although this analysis used a probability sample of members, the results are limited by the exclusion of data for the $5 \%$ of profiles that were private. Female users were more likely to have private profiles ( $82 \%$, in contrast to $75 \%$ for public profiles) and younger users are probably also more likely to have private profiles and so there may be different usage patterns for private users. Moreover, the sampling does not exclude members that are currently inactive and this may bias the temporal trends, especially if, as seems likely, those that joined earlier are more likely to be inactive. Another limitation is that this analysis has not included the direct communication features of the site, such as the discussion groups and comments between users, and has not attempted a content-based analysis of the relationship between site features, such as whether friends tend to read similar books.

The decreasing trends in the graphs over time are consistent with users tending to stay active after joining, so that newer users have lower levels of each activity. There is a 
clear anomaly in the number of friends, however, with a kink in the graph at 2012 (Figure 5). A possible explanation for this kink is that Goodreads recruited in 2012 with the aid of a Facebook app, which may have altered the friending dynamic. For example, new joiners may have linked to their Facebook friends through this app.

The low correlations between book-based and social activities could be due to the absence of any relationship or due to competing relationships (e.g., users focusing on either books or friends). To investigate this issue, Figure 8 shows the extent to which the number of friends varies with the number of books read, after ranking both data sets. The absence of clusters, other than the vertical linear shapes caused by ranking ties, suggest that the relationship between books and friends is approximately random, with no clear delineation of types of user. Users that ignore the book-related features of the site but use the social features extensively are perhaps unexpected given that they could (and maybe do) use a generic SNS for this instead. Some of these might be passive consumers of the book-related features (e.g., reading reviews), may join to connect with book-loving friends that they know to be active on the site, or, as in the case of some book club members, may primarily join to make connections with likeminded people through book-related information.

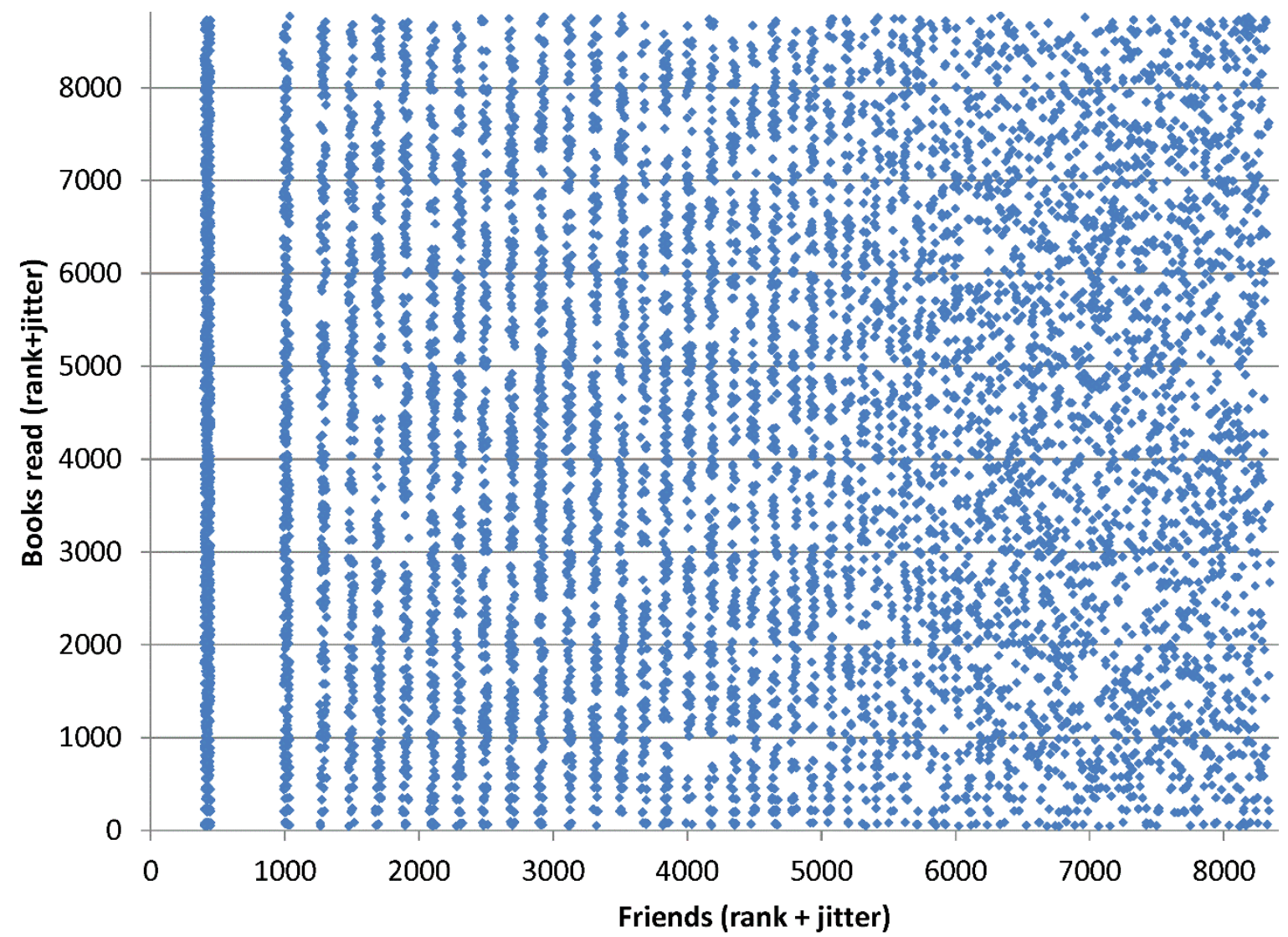

Figure 8: Books rank against friends rank for users with public profiles that joined in 2012 $(n=8,332)$. Random jitter of up to $+/-25$ is added to each point in order to reduce overlaps.

The main exception to the randomness in Figure 8 is that people that read the most books also tend to have more Friends in the site than people that read fewer books (Figure 9; see also the slight top-right hand corner cluster in Figure 8). There is therefore a small superuser group that are highly active with books and socially, whereas the other members do not fall naturally into groups by activity level. Nevertheless, although super users have many 
friends and list many books, they tend to specialise to some extent in one of the two. For example, one user had about 850 books and 650 Friends - with the friend count being higher than the book count, relative to other users.

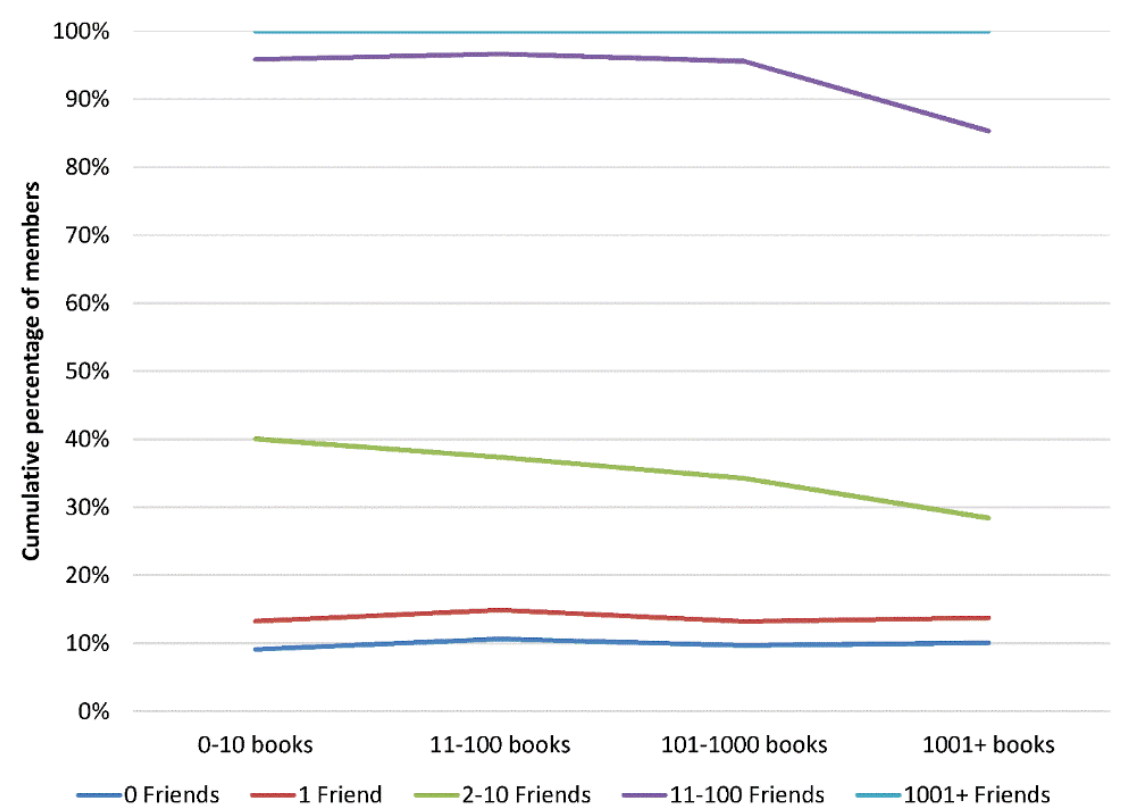

Figure 9. Books against friends grouped into bands, for users with public profiles that joined in $2012(n=8,332)$.

The analysis has treated Goodreads as a single homogeneous website but patterns of user may vary by country and so the results reported so far are likely to be affected to some extent by the international makeup of the users. For example, if some countries have a particularly high proportion of male users then the gender comparisons for the site overall might partly reflect characteristics of that country. Although it is not possible to accurately determine location information from public profiles, the people that register many books in Goodreads can also be investigated from an international dimension from lists of the top readers by country. Country information is self-reported and some is fake, however, such as a 98 year old apparently Russian woman who likes books without food stuck to them and lists exclusively English books, many with about the USA. There is almost no international relationship between average numbers of books and average numbers of friends (Figure 10). A linear relationship could perhaps have been expected and the lack of one confirms that there are likely to be different international patterns of use. For example, extensive book readers in the Middle East (including Egypt, Saudi Arabia, and Iran) seem to be particularly sociable within Goodreads. Because of this evidence of international differences, the lack of systematic nationality information is a limitation for all of the results. 


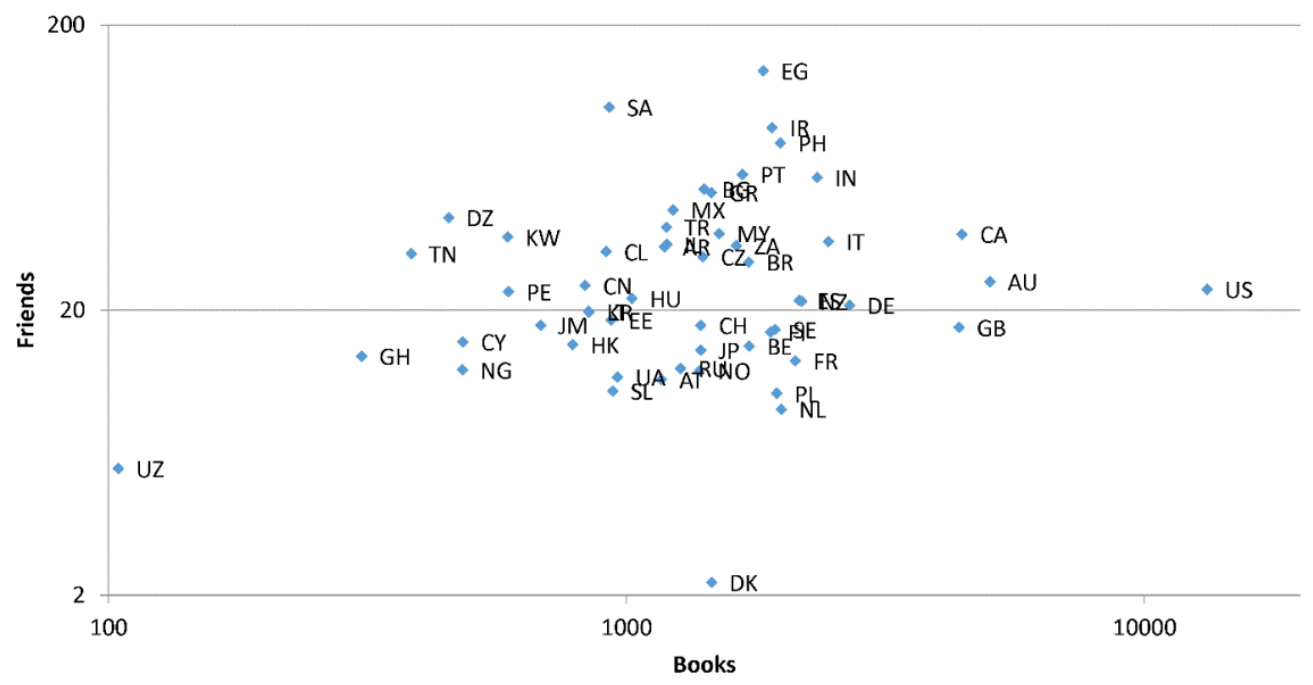

Figure 10. Average (geometric mean) numbers of friends against books registered for Goodreads users from the top 50 book readers in each country $(n=54)$ (log-log scale).

\section{Conclusions}

This article analysed Goodreads users through a random probability sample, excluding users with private profiles from most of the analyses. In partial answer to the first research question, longer term users have higher levels of activity than newer members. This is consistent either with members remaining active in the site, or with early joiners being more active than later joiners. Anecdotally, the evidence seems to suggest the former because most profiles visited manually showed evidence of recent activity. In support of this, the character of members did not change much over time in gender balance or average ratings given to books. Nevertheless, the introduction of a Goodreads Facebook app seems to have given a boost to the levels of friendship within the site.

In answer to the second research question, there is almost no trend in terms of the relationship between book-related activities and social activities. The small positive correlation between books read and friends in the site seems to be mainly due to a small number of super users with high levels of both. For the remaining users, the number of friends had no relationship with the number of books read. This suggests that each user selected their own balance of reading and friendship within the site and there is not a natural split between those who use the site mainly to catalogue books read and those who use the site mainly to socialise around books. Thus, for a few users, Goodreads is apparently a general SNS and for a few others it is a book-based website, whereas for most users it is a book-based social navigation SNS, with the user choosing their own blend of social and book-based activities.

For the third research question, although females form about three quarters of Goodreads members, there was little evidence that they used the site differently from males, at a macro level, although there is presumably a partial gender split in the genres of books read. In addition, females tended to read more books and be less positive in their reviews of books, although the differences for these were small. Thus, for users of both genders, Goodreads is a book-based social navigation SNS even though there are some differences in the way that the site is used.

Finally, Goodreads librarians tend to be much more active than typical members of the site, both socially and in terms of books registered, and so also use the site as a bookbased social navigation SNS. They tend to be longer term users of the site as well. 
In conclusion, Goodreads seems to be a book-based social navigation SNS rather than being primarily either a book website or a general SNS. It has successfully maintained the interest of its members and is particularly attractive to females. Excluding the few highly active super users, people are able to select their individual balance of social and bookfocused activities, with no combination of the two being typical for the site. This should encourage current and future members to choose their own balance of Goodreads facilities in order to best meet their own needs. The successful combination of book-based information and social activities mirrors book clubs and so educators, librarians and individuals should consider Goodreads as an alternative to book clubs in contexts where book clubs are impractical or online interactions are preferable (for additional advice, see: Hooper, 2014). Future research could explore the difference between the two approaches to combining reading with social interactions to assess whether there are contexts in which one works better than the other or a combination of the two would be advantageous. For example, perhaps online interactions within Goodreads would promote literacy more, given that social interactions in the site are necessarily text-based. Conversely, offline book clubs may be more useful for book clubs with the goal of encouraging pupils with literacy issues to read.

The gender differences in patterns of use found within the site are not substantial and so males and females do not need to consider adopting different strategies within the site. The relatively minor gender differences found are surprising given that there are substantial differences in popular reading patterns, both in the genres of books read and the genders of authors. There seems to be relatively little empirical academic research about gender differences in book-related social activities, despite the popularity of reading. Hence, there is scope for future research to assess how the different genders use the site to interact with others and to write about books. This may give more detailed insights into why gender differences in genre preferences exist. Such research would need to be cautious when interpreting comments about books, however, since readers may write reviews and comments in order to achieve social goals rather than to accurately record their opinions.

In the wider context of social web sites, Goodreads shows that there is still space for themed social navigation SNSs to be successful, despite the dominance of general SNSs like Facebook. Future research could explore whether typical Goodreads users treat it as their primary social web site or whether other sites are more important to them. In addition, the motivations of users that apparently ignore the book-based features of Goodreads would be interesting to investigate in order to understand the benefits that they derive from the site.

\section{References}

BBC (2015). Amazon targets 1,114 'fake reviewers' in Seattle lawsuit. http://www.bbc.co.uk/news/technology-34565631

Benton, P. (1995). Conflicting cultures: reflections on the reading and viewing of secondaryschool pupils. Oxford Review of Education, 21(4), 457-470.

Blackwell, J., \& Springer, M. (2013). Goodreads and adolescent engagement in reading and writing. In Society for Information Technology \& Teacher Education International Conference (Vol. 2013, No. 1, pp. 4466-4471).

Brackett, K. P. (2000). Facework strategies among romance fiction readers. The Social Science Journal, 37(3), 347-360.

Brandtzaeg, P. B., \& Heim, J. (2011). A typology of social networking sites users. International Journal of Web Based Communities, 7(1), 28-51. 
Clark, C.T., \& Blackburn, M.V. (in press). Scenes of violence and sex in recent award-winning LGBT-themed young adult novels and the ideologies they offer their readers. Discourse: Studies in the Cultural Politics of Education. Doi: 10.1080/01596306.2014.936713

Clark, C., Torsi, S., \& Strong, J. (2005). Young people and reading: A school study conducted by the national literacy trust for the reading Champions initiative. London, UK: National Literacy Trust.

Dahlgreen, W. (2014). Reading is alive and well in Britain. YouGov. https://yougov.co.uk/news/2014/04/09/reading-alive-and-well-britain/

Dai, H., Zhu, F., Lim, E. P., \& Pang, H. (2012). Detecting anomalies in bipartite graphs with mutual dependency principles. In IEEE 12th International Conference on Data Mining (ICDM 2012). Los Alamitos, CA: IEEE Press (pp. 171-180).

Desrochers, N., Quan-Haase, A., Pennington, D. R., Laplante, A., Martin, K., \& Spiteri, L. (2013). Beyond the playlist: Looking at user-generated collocation of cultural products through social tagging. Proceedings of the American Society for Information Science and Technology, 50(1), 1-4.

Dimitrov, S., Zamal, F., Piper, A., \& Ruths, D. (2015). Goodreads vs Amazon: The effect of decoupling book reviewing and book selling. In Proceedings of the Ninth International AAAI Conference on Web and Social Media, May 26-29, 2015, (pp. 602-605).Oxford University. http://piperlab.mcgill.ca/pdfs/Goodreads_ICWSM_2015.pdf

Ellison, N. B. (2007). Social network sites: Definition, history, and scholarship. Journal of Computer-Mediated Communication, 13(1), 210-230.

Flood, A. (2014). Readers prefer authors of their own sex, survey finds. Theguardian.com. http://www.theguardian.com/books/2014/nov/25/readers-prefer-authors-own-sexgoodreads-survey

Foasberg, N. M. (2012). Online reading communities: From book clubs to book blogs. The Journal of Social Media in Society, 1(1), 30-53.

Franiuk, R., \& Scherr, S. (2013). "The Lion Fell in Love with the Lamb" Gender, violence, and vampires. Feminist Media Studies, 13(1), 14-28.

Goodreads (2015a). About Goodreads. https://www.goodreads.com/about/us

Goodreads (2015b). Librarian manual. https://www.goodreads.com/librarian manual

Gruzd, A., \& Sedo, D.R. (2012). \#1b1t: investigating reading practices at the turn of the twenty-first century. Mémoires du livre/Studies in Book Culture, 3(2), https://www.erudit.org/revue/memoires/2012/v3/n2/1009347ar.html. doi: 10.7202/1009347ar

$\mathrm{Ha}, \mathrm{A}$. (2012). Reading is alive and well at social reading site Goodreads, which just hit $10 \mathrm{~m}$ members. Tech Crunch. http://techcrunch.com/2012/08/13/goodreads-10-millionmembers/

Harder, A., Howard, V., \& Sedo, D.R. (2015). Creating cohesive community through shared reading: A case study of One Book Nova Scotia. Partnership: The Canadian Journal of Library and Information Practice and Research, 10(1). http://synergies.lib.uoguelph.ca/index.php/perj/article/view/3098

Harzewski, S. (2011). Chick lit and postfeminism. Charlottesville, VA: University of Virginia Press.

Herther, N. K. (2013). Goodreads: Social media meets readers advisory. Online Searcher, 37(4), 38-41. 
Hooper, R. (2014). Using Goodreads in adult programming. Tennessee Libraries, 64(3). http://www.tnla.org/?page=TL64_3_goodreads

Hopper, R. (2005). What are teenagers reading? Adolescent fiction reading habits and reading choices. Literacy, 39(3), 113-120.

Hurst, R. (2009). The barrister's bedmate: Harlequin Mills \& Boon and the Bridget Jones Debate. Australian Feminist Studies, 24(62), 453-468.

Jeffries, S. (2008). Social cataloging tools: a comparison and application for librarians. Library Hi Tech News, 25(10), 1-4.

Katz, E., Blumler, J. G., \& Gurevitch, M. (1973). Uses and gratifications research. Public Opinion Quarterly, 37(4), 509-523.

Kovács, B., \& Sharkey, A. J. (2014). The paradox of publicity how awards can negatively affect the evaluation of quality. Administrative Science Quarterly, 59(1), 1-33.

Liu, Y., Xie, M., \& Lakshmanan, L. V. (2014). Recommending user generated item lists. In Proceedings of the 8th ACM Conference on Recommender systems (pp. 185-192). New York: ACM Press.

Long, E. (1986). Women, reading, and cultural authority: Some implications of the audience perspective in cultural studies. American Quarterly, 38(4), 591-612.

Long, E. (2003). Book clubs: Women and the uses of reading in everyday life. Chicago: University of Chicago Press.

Manuel, J., \& Carter, D. (2015). Current and historical perspectives on Australian teenagers' reading practices and preferences. Australian Journal of Language and Literacy, 38(2), 115-128.

Manuel, J., \& Robinson, D. (2003). Teenage boys, teenage girls and books: Re-viewing some assumptions about gender and adolescents' reading practices. English Teaching: Practice and Critique, 2(2), 66-77.

Manuel, J. (2012). Reading lives: Teenagers' reading practices and preferences. In: Manuel, J. \& Brindley, S. (eds.) Teenagers and reading: Literary heritages, cultural contexts and contemporary reading practices, Kent Town, South Australia: Wakefield Press (pp. 1237).

Matthews, J. C. (2015). Professionals and nonprofessionals on Goodreads: Behavior standards for authors, reviewers, and readers. New Media \& Society, doi: $10.1177 / 1461444815582141$.

Moffitt, M. A. S., \& Wartella, E. (1991). Youth and reading: A survey of leisure reading pursuits of female and male adolescents. Reading Research and Instruction, 31(2), 117.

Morrison, B. (2008). The reading cure. Thegurardian.com http://www.theguardian.com/books/2008/jan/05/fiction.scienceandnature

Moyer, J. E. (2015). Readers' advisory services as reference services. In D.A. Tyckoson \& J.G. Dove (Eds.), Reimagining reference in the 21st century (pp. 75-86). West Lafayette, Indiana: Purdue University Press.

Naik, Y. (2012). Finding good reads on Goodreads: Readers take RA into their own hands. Reference \& User Services Quarterly, 51(4), 319-323.

Nakamura, L. (2013). "Words with Friends": Socially Networked Reading on Goodreads. PMLA, 128(1), 238-243.

Nielsen (2015). Literary liaisons: Who's reading romance books? http://www.nielsen.com/us/en/insights/news/2015/literary-liaisons-whos-readingromance-books.html 
Olanoff, D. (2013). Amazon acquires social reading site Goodreads, which gives the company a social advantage over Apple. TechCrunch, http://techcrunch.com/2013/03/28/amazon-acquires-social-reading-site-goodreads/

O'Leary, M. (2012). Reading dead? No way! See Goodreads. Information Today, 29(1), 2223.

Owen, M. (1997). Re-inventing romance: reading popular romantic fiction. Women's Studies International Forum, 20(4), 537-546.

Peplow, D. (2016). Talk about books: A study of reading groups. London, UK: Bloomsbury Publishing.

Radway, J. (1984). Reading the romance: Woman, patriarchy and popular literature. Chapel Hill, NC: University of North Carolina Press.

Rogers, E. M. (2010). Diffusion of innovations (5th edition). New York: Simon \& Schuster International.

Ryan, B., \& Gross, N. C. (1943). The diffusion of hybrid seed corn in two lowa communities. Rural Sociology, 8(1), 15-24.

Qasim, A., \& Qasim, Z. (2013). Gender construction in the twentieth century funny quotes. In International Conference on Women's Studies (ICWS2013). Colombo, Sri Lanka: International Centre for Research \& Development (pp. 183-201).

Scharber, C. (2009). Online book clubs: Bridges between old and new literacies practices. Journal of Adolescent \& Adult Literacy, 52(5), 433-437.

Schultheis, C. (1990). A study of the relationship between gender and reading preferences in adolescents. Kent State University, MA thesis.

Sedo, D. R. (2003). Readers in reading groups an online survey of face-to-face and virtual book clubs. Convergence: The International Journal of Research into New Media Technologies, 9(1), 66-90.

Sedo, D. R. (2011). An introduction to reading communities: Processes and formations. In D.R. Sedo (Ed.), Reading Communities from Salons to Cyberspace (pp. 15-41). New York, NY: Palgrave Macmillan.

Sharick, C. (2007). Top 10 websites \#5. Goodreads.com. http://content.time.com/time/specials/2007/article/0,28804,1686204_1686305_1691 $167,00$. html

Stover, K. M. (2009). Stalking the wild appeal factor g readers' advisory and social networking sites. Reference and User Services Quarterly, 48(3), 243-246+269.

Tarulli, L., \& Caplinger, V. A. (2013). In the eye of the beholder: Readers' advisory from a cataloging perspective. Reference and User Services Quarterly, 52(4), 287-290.

Thelwall, M. (2008). Social networks, gender and friending: An analysis of MySpace member profiles, Journal of the American Society for Information Science and Technology, 59(8), 1321-1330.

Thelwall, M. (2009a). Homophily in MySpace, Journal of the American Society for Information Science and Technology, 60(2), 219-231.

Thelwall, M. (2009b). Social network sites: Users and uses. In: M. Zelkowitz (Ed.), Advances in Computers, 76. Amsterdam: Elsevier (pp. 19-73).

Thomas, G. J. (2007). Romance: The perfect creative industry? A case study of HarlequinMills and Boon Australia. In Goade, Sally (Ed.) Empowerment versus Oppression: Twenty First Century Views of Popular Romance Novels. Cambridge, UK: Cambridge Scholars Publishing (pp. 20-29). 
Verboord, M. (2011). Cultural products go online: Comparing the internet and print media on distributions of gender, genre and commercial success. Communications, 36(4), 441-462.

Whittingham, J. L., \& Huffman, S. (2009). The effects of book clubs on the reading attitudes of middle school students. Reading Improvement, 46(3), 130-136.

Wilkinson, D. \& Thelwall, M. (2010). Social network site changes over time: The case of MySpace. Journal of the American Society for Information Science and Technology, 61(11), 2311-2323.

Worrall, A. (2013). "Back onto the tracks": Convergent community boundaries in LibraryThing and Goodreads. In 9th Annual Social Informatics Research Symposium: The Social Informatics of Information Boundaries, 76th ASIS\&T Annual Meeting, Montreal,

Canada. http://www.adamworrall.org/portfolio/publications/worrall_convergent_community_ boundaries_asist_2013_sigsi_preprint_101413.pdf

Wu, H. H. (2013). Gender, romance novels and plastic sexuality in the United States: A focus on female college students. Journal of International Women's Studies, 8(1), 125-134.

Wyatt, N. (2009). Finding good reads on Goodreads. Reference \& User Services Quarterly, 48(3), 319-323.

Zickuhr, K. \& Rainie, L. (2014). E-reading rises as device ownership jumps. Pew Research Center. http://www.pewinternet.org/2014/01/16/e-reading-rises-as-deviceownership-jumps/

Zuccala, A. A., Verleysen, F. T., Cornacchia, R., \& Engels, T. C. (2015). Altmetrics for the humanities: Comparing Goodreads reader ratings with citations to history books. Aslib Journal of Information Management, 67(3), 320-336.

Zuccala, A., Verleysen, F., \& Engels, T. (2014). The societal impact of history texts: Lay readership and the 'altmetric' value of Goodreads. In 19th Nordic Workshop on Bibliometrics and Research Policy Reykjavik, University of Iceland, Reykjavik. http://www.rannis.is/media/erindi-fyrirlesara/8-NordicWorkshop-Zuccala-et-al-15-0614.pdf. 